\title{
Alcohol Intolerance
}

National Cancer Institute

\section{Source}

National Cancer Institute. Alcohol Intolerance. NCI Thesaurus. Code C78167.

Increased sensitivity to the adverse effects of alcohol, which can include nasal

congestion, skin flushes, heart dysrhythmias, nausea, vomiting, indigestion and headaches. 